\title{
Microalbuminuria and Kidney Disease Risk in HIV Patients Taking Combined Antiretroviral Therapy
}

\author{
Huylmer Lucena Chaves ${ }^{1}$, Mayanna Pinho Batista ${ }^{1}$, Adriana de Menezes Gomes ${ }^{1}$, \\ Amanda Antunes Costa ${ }^{1}$, André Tigre Lima ${ }^{1}$, Vinícius Diniz Arcelino do Ceará1, \\ Pedro Rubens Araújo Carvalho', Linna Albuquerque Sampaio', \\ Fabrício de Maicy Bezerra1,2,3, Melissa Soares Medeiros ${ }^{1,2,3}$ \\ ${ }^{1}$ Medicine School, Unichristus, Fortaleza, Brazil \\ ${ }^{2}$ Fortaleza General Hospital, Fortaleza, Brazil \\ ${ }^{3}$ São Jose Hospital of Infectious Diseases, Fortaleza, Brazil \\ Email: melmedeiros@hotmail.com
}

Received 5 April 2014; revised 5 May 2014; accepted 30 May 2014

Copyright (C) 2014 by authors and Scientific Research Publishing Inc. This work is licensed under the Creative Commons Attribution International License (CC BY). http://creativecommons.org/licenses/by/4.0/

\section{Open Access}

\section{Abstract}

Objectives: This study proposes to evaluate risk factors for kidney disease in HIV patients treated chronically and correlate with microalbuminuria measurements. Methods: Review charts and analyses of microalbuminuria in subgroup of HIV patients treated at Ceara/Brazil. Results: 149 patients, 69.1\% male, mean 38.5 years old, infection mean 86.8 months. Mean Creatinine Clearance $110.2 \%$, Creatinine 0.97 , Urea $27.76 \mathrm{mg} / \mathrm{dl}, \mathrm{CD} 4+600.37 \mathrm{cels} / \mathrm{mm}^{3}$ and detectable viral load 530.59 copies with $61.7 \%$ undetectable. Mean Dosages of microalbuminuria/24h 147, 46 \pm 820, $45(\mathrm{~N}=48)$ and microalbuminuria $(\mathrm{mg} / \mathrm{dl}) 32.05 \pm 85.25(\mathrm{~N}=43)$. Kidney Diseases Classification analyses evidenced $6.4 \%$ patients in stages $\geq 3$ and $6.2 \%$ presented altered Microalbuminuria/24h. Patients using Tenofovir (TDF) 27.27\% had Stage 2 and protease inhibitors (PI) had 4.1\% in Stage 3. Proteinuria was observed in $5 \%$ stage $\geq 3$. Association PI/TDF had $4.1 \%$ in Stage 3 . No statistical difference between CD4 > or $<350$ cels $/ \mathrm{mm}^{3}$ and microalbuminuria $/ 24 \mathrm{~h}>300 \mathrm{mg}(\mathrm{p}=0.69)$; detectable/undetectable viral load and microalbuminuria/24h $(p=0.63)$ or stage $\geq 3(p=0.17)$; relation to Diabetes or arterial hypertension and microalbuminuria $24 \mathrm{~h}(\mathrm{p}=0.5$ and $\mathrm{p}=0.21)$; relation stage $\geq 3$ and microalbuminuria $/ 24 \mathrm{~h}(\mathrm{p}=0.33)$; relation HIV diagnoses $>/<60$ months and stage $\geq 3(p=0.51)$; or microalbuminuria/24h and TDF $(p=0.4)$, PI $(p=1)$, TDF $/$ PI $(p=0.69)$, Atazanavir $(p=0.4)$ or Lopinavir/r $(p=1)$ regimens. There was statistical significance comparing age $>$ or $<50$ years and stage $\geq 3(p=0.001)$ without difference with age $>$ or $<50$ years and microalbuminuria/24h ( $\mathrm{p}=\mathbf{0 . 5 5}$ ) or microalbuminuria $\mathrm{mg} / \mathrm{d}(\mathrm{p}=\mathbf{0 . 3 2})$. Relating comorbidities risk (Diabetes Mellitus plus Systemic Arterial Hypertension) to Kidney Diseases, it was found that $\mathbf{5 5 . 5 \%}$ patients in Stage 3 or above with comorbidities compared with 15\% with comorbidities in lower 
stages $(P=0.005)$. Nevertheless, comorbidities presence was not associated with microalbuminuria $(p=0.08)$. Conclusion: Kidney disease is a real risk for HIV patients and stages $\geq 3$ have to be early detected. Microalbuminuria dosage did not demonstrate more sensibility than proteinuria to early diagnoses, even related to antiretroviral drugs. Major risk factor for kidney damage evidenced to be older than 50 years and there was no protective effect from CD4 or undetectable viral load.

\section{Keywords}

HIV, AIDS, Antiretroviral, Kidney Disease, Microalbuminuria

\section{Introduction}

Aids pandemic is one of the most important causes of human mortality and hospital admission, even today, after more than 30 years of infection [1]. Last epidemiologic data evidenced higher infection dissemination in 1986, with 3.5 millions of new infections [2]. But in 2008 a total of 2.7 million new infections occurred and millions of people died with Aids around the world in 2009. Besides this period evidenced a growing number of persons taking antiretroviral therapy, which permitted an epidemic and mortality control [2].

Actual antiretroviral therapy can control appropriate viral replication and partially recover Immune System, avoiding diseases progression to AIDS symptoms. But sterilizing cure is not achieved nowadays with current available drugs, specifically due to reservoirs sites in latent cells or probably low levels of viral replication [3].

Besides an improvement in morbidity and mortality in HIV infected patients, this increased survival revealed others issues as early and late drugs toxicity [4]. Referred as late toxicity we have Metabolic Syndrome, Lipodystrophy, Bone mass loss and Kidney disease [5] [6].

Kidney Disease (KD) is manifested frequently as urine protein loss or creatinine increase related as complication of HIV infection. High levels of protein loss evidenced worst results, including higher hospital entrance and mortality. Three different studies evidenced high prevalence of microalbuminuria in HIV infected patients, values referred as $19 \%, 30 \%$ and $34 \%$. One of them suggested that symptomatic individuals could have higher risk for microalbuminuria [7]. Since these, antiretroviral therapy has been improving each year and new drugs are available frequently, so kidney damage must be monitored frequently.

Increase in albumin urine excretion, even in microalbuminuria level, is an independent risk for cardiovascular disease (CVD) and Chronic Renal Failure (CRF), with higher mortality in general population and HIV individuals. Occurrences of Kidney diseases in HIV people could be also consequence of drugs toxicity, opportunistic infections, and comorbidities as Systemic Arterial Hypertension, Diabetes Mellitus and Hepatitis C coinfection. Tenofovir inclusion as the first-line antiretroviral therapy was recently recommended by World Health Organization, so risk for kidney diseases may increase in the next years [8]. There is evidence that microalbuminuria could represent an early marker of HIV infection for higher risk of CVD and CRF [9]. Studies in post HAART era evidenced prevalence between $8.7 \%$ and $11 \%$ in HIV infected patients [10] [11]. The aim of this study is to evaluate kidney damage and renal failure of HIV chronic treated infected patients and correlate with microalbuminuria as a maker, considering risk factors as antiretroviral drugs and comorbidities.

\section{Methodology}

\subsection{Study Setting and Design}

Population under analysis consisted in HIV/AIDS patients attended at Fortaleza General Hospital, Ceara, Brazil. This is a reference site to attend HIV infected patients at Ceara and it represents $10 \%$ of all diagnosed people in this state. We analyzed three hundred and thirty-six files, and one hundred and forty-nine patients had completed data specifications. Samples of forty-three patients were analyzed to microalbuminuria dosage, in a period from January to December 2013 randomly. This was a retrospective study, with chart files review, and therefore consent term was not demanded. 


\subsection{Data Collection and Analysis}

Sociodemographic data were collected by a closed questionnaire comprising age, sex, use of antiretroviral drugs, occurrence of opportunistic infections, comorbidities, CD4+ T cells count and Viral load. Laboratory assays collected were serum creatinine, serum urea, urine analysis and microalbuminuria in 24 hours. Autoanalyzer manufacturers and clinical laboratories were used to process the samples with regular calibration. Urine volume was collected during 24 hours previous to exam's process.

Kidney damage was classified by Creatinine Clearance (ClCr) measurement using Crockoft-Gault calculation (Table 1) [12].

Statistical Package calculated data results analysis for the Social Sciences (SPSS, version 16) for frequency analysis, followed by chi-square and fisher test considering $\mathrm{p}<0.05$ for significance level.

\section{Results}

\subsection{Demographic Characteristics of Population}

One hundred and forty-nine patients were evaluated. Gender distribution comprised 103 (69.1\%) males and 46 (39.9\%) females. General age mean was 38.5 years, males’ mean $37.8( \pm 11.6)$ and females’ mean $40.1( \pm 10.4)$ years. Mean time of infection was 65.77 months, with males’ $65.16( \pm 37.04)$ and females’ 61.15 (63.35). Mean CD4+ T cells and Viral Load were respectively 600.37 cells $/ \mathrm{mm}^{3}$ and 530.59 copies $/ \mathrm{ml}$, with $61.7 \%$ viral load under 40 copies. There was no statistical difference between groups (Table 2).

Kidney function evaluation evidenced mean creatinine $0.97 \pm 1.34$ with Creatinine Clearance $110.2 \pm 44.6$ and Urea $27.76 \pm 10.3$, without statistical differences between groups (Table 3).

Table 1. Kidney disease outcomes quality initiative kidney diseases classification.

\begin{tabular}{ccc}
\hline Stage & Kidney function & Clcr $\left(\mathrm{ml} / \mathrm{min}^{\prime} / 1.73 \mathrm{~m}^{2}\right)$ \\
\hline 1 & Kidney damage (microalbuminuria, proteinuria), preserved function, with risk factors & $>90$ \\
2 & Kidney damage with low renal insufficiency & $60-89$ \\
3 & Kidney damage with moderate renal insufficiency & $30-59$ \\
4 & Kidney damage with severe renal insufficiency & $15-29$ \\
5 & Kidney damage with terminal renal insufficiency or dialysis & $<15$ \\
\hline
\end{tabular}

Table 2. Demographic and immunovirologic characteristcs $(n=149)$.

\begin{tabular}{|c|c|c|c|c|}
\hline Characteristic Mean & $\begin{array}{c}\text { Male } \\
(n=103)\end{array}$ & $\begin{array}{l}\text { Female } \\
(\mathrm{n}=46)\end{array}$ & $\begin{array}{l}\text { Total } \\
\text { Mean }\end{array}$ & $P$ value \\
\hline Age-Years & $37.8( \pm 11.6)$ & $40.1( \pm 10.4)$ & 38.5 & 0.24 \\
\hline Months living with HIV & $65.16( \pm 37.04)$ & $61.15( \pm 63.35)$ & 65.77 & 0.73 \\
\hline $\mathrm{CD} 4+\mathrm{T}$ cell- $-\mathrm{cel} / \mathrm{mm}^{3}$ & $572.72( \pm 260.03)$ & $597.84( \pm 300)$ & 600.37 & 0.62 \\
\hline Viral Load_copies/ml & $\begin{array}{c}324.35( \pm 15307.5) \\
\text { under } 40 \text { copies—-51 (71.8\%) }\end{array}$ & $\begin{array}{c}627.24( \pm 28913.4) \\
\text { under } 40 \text { copies-20 }(28.2 \%)\end{array}$ & 530.59 & 0.05 \\
\hline
\end{tabular}

Table 3. Serum laboratory analysis of HIV/AIDS patients $(n=149)$.

\begin{tabular}{cccc}
\hline Characteristic Mean & $\begin{array}{c}\text { Male } \\
(\mathrm{n}=103)\end{array}$ & $\begin{array}{c}\text { Female } \\
(\mathrm{n}=46)\end{array}$ & $\begin{array}{c}\text { Total } \\
\text { Mean }\end{array}$ \\
\hline Serum Creatinine $\mathrm{mg} / \mathrm{dL}$ & $0.76( \pm 0.2)$ & $1.07( \pm 1.6)$ & $0.97( \pm 1.3)$ \\
Creatinine Clearence $\mathrm{ml} / \mathrm{min} / 1.73 \mathrm{~m}^{2}$ & $112.79( \pm 44.92)$ & $104.66( \pm 43.88)$ & $110.2( \pm 44.6)$ \\
Serum Urea & $28.86( \pm 8.05)$ & $25.27( \pm 13.92)$ & $27.76( \pm 10.3)$ \\
Serum Creatinine $\mathrm{mg} / \mathrm{dL}$ & $0.76( \pm 0.2)$ & $1.07( \pm 1.6)$ & 0.05 \\
\hline
\end{tabular}




\subsection{Microalbuminuria and Kidney Dysfunction Evaluation}

Analysis of microalbuminuria demonstrated mean microalbuminuria (mg/ml) $32.05 \pm 85.25$ and microalbuminuria/24h $147.46 \pm 820.45$. Altered microalbuminuria/24h, defined as above 300 , was detected in $8 \%(n=12)$ of total patients. Comparing groups with normal and altered microalbuminuria/24h there was no statistical difference for age, sex, comorbidities, Viral Load and CD4+ T cell count (Table 6), (Graphic 1 and Graphic 2).

A proportion of $6.4 \%(n=140)$ was detected equal or superior to Stage 3 and $6.2 \%$ patients had altered microalbuminuria/24h. But, there was no statistical significance correlating microalbuminuria/24h and Stage 3 or above $(\mathrm{p}=0.33)$. Evaluating microalbuminuria $\mathrm{mg} / \mathrm{dl}$ we detected $11.6 \%$ prevalence, but with no correlation to Stage 3 or above $(\mathrm{p}=0.31)$. Urine analysis is evidenced in Table 4.

Evaluating Viral load related to Stage 3 or above, there was no difference between viral load detectable or not $(\mathrm{p}=0.17)$, and presence of microalbuminuria/24h $(\mathrm{p}=0.63)$. There was also no correlation to CD4 below or above 350 cels $/ \mathrm{mm}^{3}$ and microalbuminuria/24h $(\mathrm{p}=0.6)$, (Table 5).

In microalbuminuria analysis, mean age was $44.8( \pm 12.13)$ years. It was statistic significant has age above 50 years and Stage $3(p=0.001)$, but just $5.7 \%$ patients under 50 years and $10 \%$ above had microalbuminuria/24h $(\mathrm{p}=0.55)$. Relating comorbidities risk (Diabetes Mellitus plus Systemic Arterial Hypertension) to Kidney Diseases, it was found 55.5\% patients in Stage 3 or above with comorbidities compared with 15\% with comorbidities in lower stages $(\mathrm{P}=0.005)$ (Table 6$)$. Nevertheless, comorbidities presence was not associated with microalbuminuria $(\mathrm{p}=0.08)$.

Comparing period living with HIV, diagnoses after and before five years was not significant risk for microalbuminuria $(\mathrm{p}=0.51)$. When evaluated drugs used in antiretroviral therapy, Tenofovir (TDF) was associated with Stages $1(84.3 \%)$ and $2(27.2 \%),(\mathrm{p}=0.4)$, protease inhibitors $(\mathrm{PI})$ with Stage $1(69.7 \%)$ and $2(23.2 \%),(\mathrm{p}=$ 0.45). Association PI/TDF was presented in 58.3\% in Stage 1 and 37.5\% Stage $2(\mathrm{p}=0.79)$. There was no correlation with microalbuminuria/24h and use of TDF $(p=0.4), \operatorname{PI}(p=1), \operatorname{PI} / T D F(p=0.69)$, Atazanavir $(p=0.4)$ or Lopinavir/r $(\mathrm{p}=1)$. Therefore, new drugs seem not to alter this laboratory finding (Table 7).

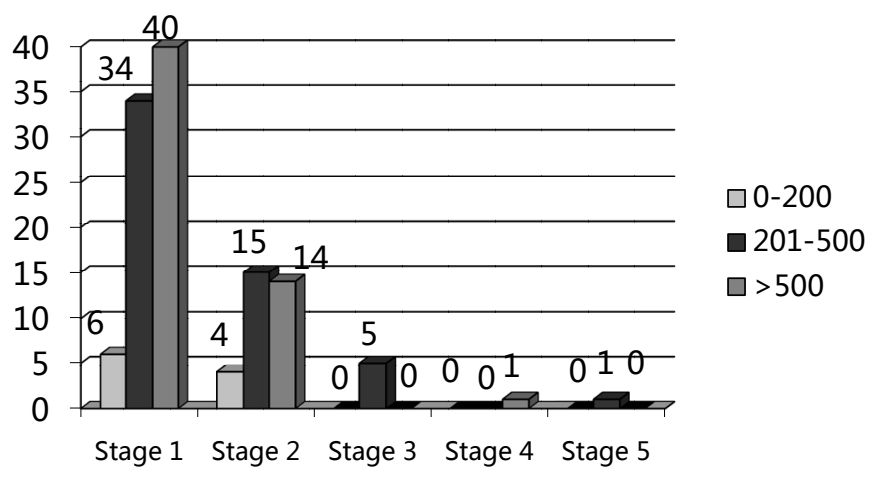

Graphic 1. CD4 count cell correlation to kidney damage classification stages.

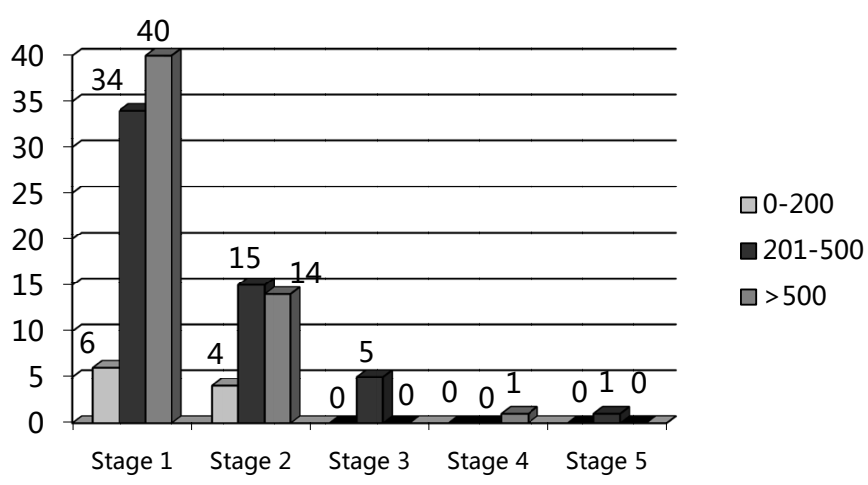

Graphic 2. Viral load correlation to kidney damage classification stages. 
Table 4. Urine analysis alterations described in HIV patients submitted to microalbuminuria assay.

\begin{tabular}{ccc}
\hline Variable & N & $\%$ \\
\hline Leucocyts presence & 4 & 10 \\
Hemace presence & 6 & 15 \\
Protein presence & 2 & 5 \\
Blood traces & 4 & 10 \\
Leucocyts trace & 11 & 27.5 \\
Bilirrubin trace & 1 & 2.5 \\
Glicoses presence & 1 & 2.5 \\
\hline
\end{tabular}

Table 5. Classification kidney disease in samples from HIV patients and comorbities.

\begin{tabular}{cccc}
\hline Classification & Total patients $(\mathrm{N})$ & Systemic Arterial Hypertension N (\%) & Diabetes Mellitus N(\%) \\
\hline Stage 1 & 102 & $10(9.8 \%)$ & $4(3.9 \%)$ \\
Stage 2 & 36 & $3(8.3 \%)$ & $1(2.7 \%)$ \\
Stage 3 & 7 & $4(57.1 \%)$ & $1(14.2 \%)$ \\
Stage 4 & 1 & 0 & 0 \\
Stage 5 & 1 & 0 & 0 \\
Total & 147 & 17 & 6 \\
\hline
\end{tabular}

Table 6. Microalbuminuria analysis related to risk factors in HIV/AIDS patients.

\begin{tabular}{|c|c|c|c|}
\hline Variable & $\begin{array}{l}\text { Microalbuminuria/24h } \\
<300 \mathrm{mg}\end{array}$ & $\begin{array}{l}\text { Microalbuminuria/24h } \\
>300 \mathrm{mg} /\end{array}$ & $P$ value \\
\hline Age mean years & $43.5( \pm 11.07)$ & $50.33( \pm 15.44)$ & 0.07 \\
\hline Female & 19 & 4 & \multirow{2}{*}{0.45} \\
\hline Male & 35 & 8 & \\
\hline HAS $(n=66)$ & 11 & 4 & 0.21 \\
\hline $\mathrm{DM}(\mathrm{n}=66)$ & 7 & 4 & 0.52 \\
\hline Comorbidities $(\mathrm{n}=24)$ & 16 & 8 & 0.08 \\
\hline \multicolumn{4}{|l|}{$\mathrm{CD} 4(\mathrm{n}=62)$} \\
\hline$>500$ & 26 & 5 & 0.5 \\
\hline$<500$ & 25 & 6 & \\
\hline \multicolumn{4}{|l|}{ Viral load $(\mathrm{n}=59)$} \\
\hline$<40$ copies & 30 & 9 & 0.1 \\
\hline Detectable & 18 & 2 & \\
\hline
\end{tabular}

Table 7. Comparing antiretroviral drugs and kidney diseases stage classification.

\begin{tabular}{|c|c|c|c|c|c|}
\hline Drugs Association & Stage $1(\mathrm{~N})$ & Stage $2(\mathrm{~N})$ & Stage $3(\mathrm{~N})$ & Stage $4(\mathrm{~N})$ & Stage $5(\mathrm{~N})$ \\
\hline Tenofovir & 54 & 9 & 1 & 0 & 0 \\
\hline Others NRTI & 33 & 24 & 6 & 1 & 1 \\
\hline Protease Inhibitors & 30 & 10 & 2 & 1 & 0 \\
\hline Others ARV & 57 & 23 & 5 & 0 & 1 \\
\hline $\mathrm{PI} / \mathrm{TDF}$ & 14 & 9 & 1 & 0 & 0 \\
\hline Other associations & 73 & 24 & 6 & 1 & 1 \\
\hline Atazanavir & 2 & 0 & 0 & 0 & 0 \\
\hline Atazanavir/ritonavir & 13 & 6 & 2 & 0 & 0 \\
\hline Lopinavir/ritonavir & 12 & 2 & 0 & 0 & 0 \\
\hline
\end{tabular}

NRTI: nucleoside analogues reverse transcriptase inhibitors; ARV: antiretroviral; TDF: tenofovir, PI: Protease Inhibitors 


\section{Discussion}

In general population, metabolic syndrome has been associated with high rates of albumin urine loss, and this syndrome has been reported recently growing in HIV infected patients. HADIGA et al. (2013) [13] identified microalbuminuria in 26.9\% of patients with Metabolic Syndrome, suggesting this condition contribution to kidney damage in HIV. And just one negative sample for microalbuminuria had negative predictive value of $98 \%$ and a positive sample $74 \%$ of positive predictive value.

Szczech et al. (2007) [7], evidenced HIV infection as an independent risk factor for microalbuminuria, and suggested it could be a sign of endothelial dysfunction and microvascular disease and not an advanced HIV infection, predicting a future vascular risk. Some factors may contribute to early renal diseases as nephropathy due to HIV, Diabetes Mellitus and Arterial Systemic Hypertension and endothelial dysfunction. This study also associated NNRTI drugs and microalbuminuria but not so strong as HOMA parameters (insulin resistance, Diabetes Mellitus) and CD4 cell count. In the present study we also found association of kidney damage with presence of comorbidities (Diabetes Mellitus as Arterial Systemic Hypertension), but not altered microalbuminuria.

The present study did not find any correlation of microalbuminuria and drug association, even nephrotoxic ones as tenofovir. BAEKKEN, et al. (2008) [9] found the same results, but evidenced a higher prevalence of microalbuminuria in HIV infected patients (8.7\%, three to five folds than general population). The period living with HIV infection, serum beta 2 microglobulin and blood systolic pressure were independent risk factor for microalbuminuria, suggesting that kidney damage may have an HIV infection component, probably and endothelial dysfunction.

WYATT et al. (2010) [14] correlated microalbuminuria and mortality risk in HIV patients, even considering advanced HIV diseases. This suggests that maybe microalbuminuria presence could be a non-invasive test for mortality risk.

Another study detected a possible faster progression of microalbuminuria to protein loss in urine in HIV infected patients, and antiretroviral therapy was a remission factor to protein loss. This fact was more impacting in women taking antiretroviral [15]. This is very concerning in our study, since a higher number of women population was not full suppressed with antiretroviral drugs, but we could not find a correlation with higher risk for microalbuminuria or even kidney damage.

\section{Conclusions}

The present study did not detect a higher level of kidney diseases in a chronic treated HIV population. Besides a microalbuminuria proportion found compared with reviewed articles, it was not correlated with higher risk for kidney damage. We detected a strong correlation of comorbidities presence and age over 50 years with significant kidney function damage. It is important to keep evaluation on this correlation with microalbuminuria getting more patients laboratory results and compare inflammatory markers more specific for endothelial damage.

Kidney diseases are a real serious problem among HIV patients and precocious damage detection and prevention monitoring techniques are recommended to avoid this complication. This is particularly important with high spread use of nephrotoxic drugs. We recommend regular dosage of serum markers and creatinine clearance calculation in clinic follow-up, besides urine analyses. In higher risk individuals, microalbuminuria dosage may be helpful to detect protein loss before kidney damage symptoms.

\section{Conflicts of Interest}

The authors declare no interest conflicts.

\section{References}

[1] Barré-Sinoussi, F. (2003) The Early Years of HIV Research: Integrating Clinical and Basic Research. Nature Medicine, 9, 844-846.

[2] Attia, S., Egger, M., Müller, M., Zwahalen, M. and Low, N. (2009) Sexual Transmission of HIV According to Viral Load and Antiretroviral Therapy: Systematic Review and Meta-Analysis. AIDS, 23, 1397-404. http://dx.doi.org/10.1097/QAD.0b013e32832b7dca

[3] ART-CC (2008) Antiretroviral Cohort Collaboration. Lancet, 372, 293-299. 
[4] Kline, E.R., Kleinhenz, D.J., Liang, B., Dikalov, S., Guidot, D.M., Hart, C.M., Jones, D.P. and Sutliff, R.L. (2008) Vascular Oxidative Stress and Nitric Oxide Depletion in HIV-1 Transgenic Rats Are Reversed by Glutathione Restoration. American Journal of Physiology. Heart and Circulatory Physiology, 294, 2792-2804. http://dx.doi.org/10.1152/ajpheart.91447.2007

[5] Aboud, M., Elgalib, Z., Kulasegaram, R. and Peters, B. (2007) Insulin Resistance and HIV Infection: A Review. International Journal of Clinical Practice, 61, 463-472. http://dx.doi.org/10.1111/j.1742-1241.2006.01267.x

[6] Jiang, J., Fu, W., Wang, X.H., Lin, P., Yao, Q. and Chen, C. (2010) HIV Gp120 Induces Endothelial Dysfunction in Tumour Necrosis Factor-a-Activated Porcine and Human Endothelial Cells. Cardiovascular Research, 87, 366-374. http://dx.doi.org/10.1093/cvr/cvq013

[7] Szczech, L.A., Grunfeld, C., Scherzer, R., Canchola, J.A., Horst, C., Sidney, S., Wohl, D. and Shlipakb, M.G. (2007) Microalbuminuria in HIV Infection. AIDS, 21, 1003-1009. http://dx.doi.org/10.1097/QAD.0b013e3280d3587f

[8] Msango, L., Downs, J.A., Kalluvya, S.E., Kideny, B.R., Kabangila, R., Johnson, Jr., W.D., Fitzgerald, D.W. and Pecka, R.N. (2011) Renal Dysfunction among HIV-Infected Patients Starting Antiretroviral Therapy. AIDS, 25, 1421-1425. http://dx.doi.org/10.1097/QAD.0b013e328348a4b1

[9] Baekken, M., Os, I., Sandvik, L. and Oektedalen, O. (2008) Microalbuminuria Associated with Indicators of Inflammatory Activity in an HIV-Positive Population. Nephrology Dialysis Transplantation, 23, 3130-3137. http://dx.doi.org/10.1093/ndt/gfn236

[10] Kim, P.S., Woods, C., Dutcher, L., Georgoff, P., Rosenberg, A., Mican, J.A.M., Kopp, J.B. and Smith, M.A. (2011) Increased Prevalence of Albuminuria in HIV-Infected Adults with Diabetes. Plos One, 6, 1-7.

[11] Ryom, L., Mocroft, A., Kirk, O., Worm, S.W., Kamara, D.A., Reiss, P., Ross, M., Fux, C.A., Morlat, P., Moranne, O., Smith, C., Lundgren, J.D. and D:A:D Study Group (2013) Association between Antiretroviral Exposure and Renal Impairment among HIV-Positive Persons with Normal Baseline Renal Function: The D:A:D Study. The Journal of Infectious Diseases, 207, 1359-1369. http://dx.doi.org/10.1093/infdis/jit043

[12] National Kidney Foundation (2002) K/DOQI Clinical Practice Guidelines for Chronic Kidney Disease: Evaluation, Classification and Stratification. American Journal of Kidney Diseases, 39, S1-266.

[13] Hadigan, C., Edwards, E., Rosenberg, A., Purdy, J.B., Fleischman, E., Howard, L., Mican, J.A. M., Sampath, K., Oyalowo, A., Johnson, A., Adler, A., Rehm, C., Smith, M., Lai, L. and Kopp, J.B. (2013) Microalbuminuria in HIV Disease. American Journal of Nephrology, 37,443-451. http://dx.doi.org/10.1159/000350384

[14] Wyatt, C.M., Hoover, D.R., Shi, Q., Seaberg, E., Wei, C., Tien, P.C., Karim, R., Lazar, J., Young, M.A., Cohen, M.H., Klotman, P.E. and Anastos, K. (2010) Microalbuminuria Is Associated with All-Cause and AIDS Mortality in Women With HIV Infection. Journal of Acquired Immune Deficiency Syndromes, 55, 73-77. http://dx.doi.org/10.1097/QAI.0b013e3181cc1070

[15] Szczech, L.A., Menezes, P., Quinlivan, E.B., Horst, C., Bartlett, J.A. and Svetkey, L.P. (2010) Microalbuminuria Predicts Overt Proteinuria among Patients with HIV Infection. HIV Medicine, 11, 419-426. 
Scientific Research Publishing (SCIRP) is one of the largest Open Access journal publishers. It is currently publishing more than 200 open access, online, peer-reviewed journals covering a wide range of academic disciplines. SCIRP serves the worldwide academic communities and contributes to the progress and application of science with its publication.

Other selected journals from SCIRP are listed as below. Submit your manuscript to us via either submit@scirp.org or Online Submission Portal.
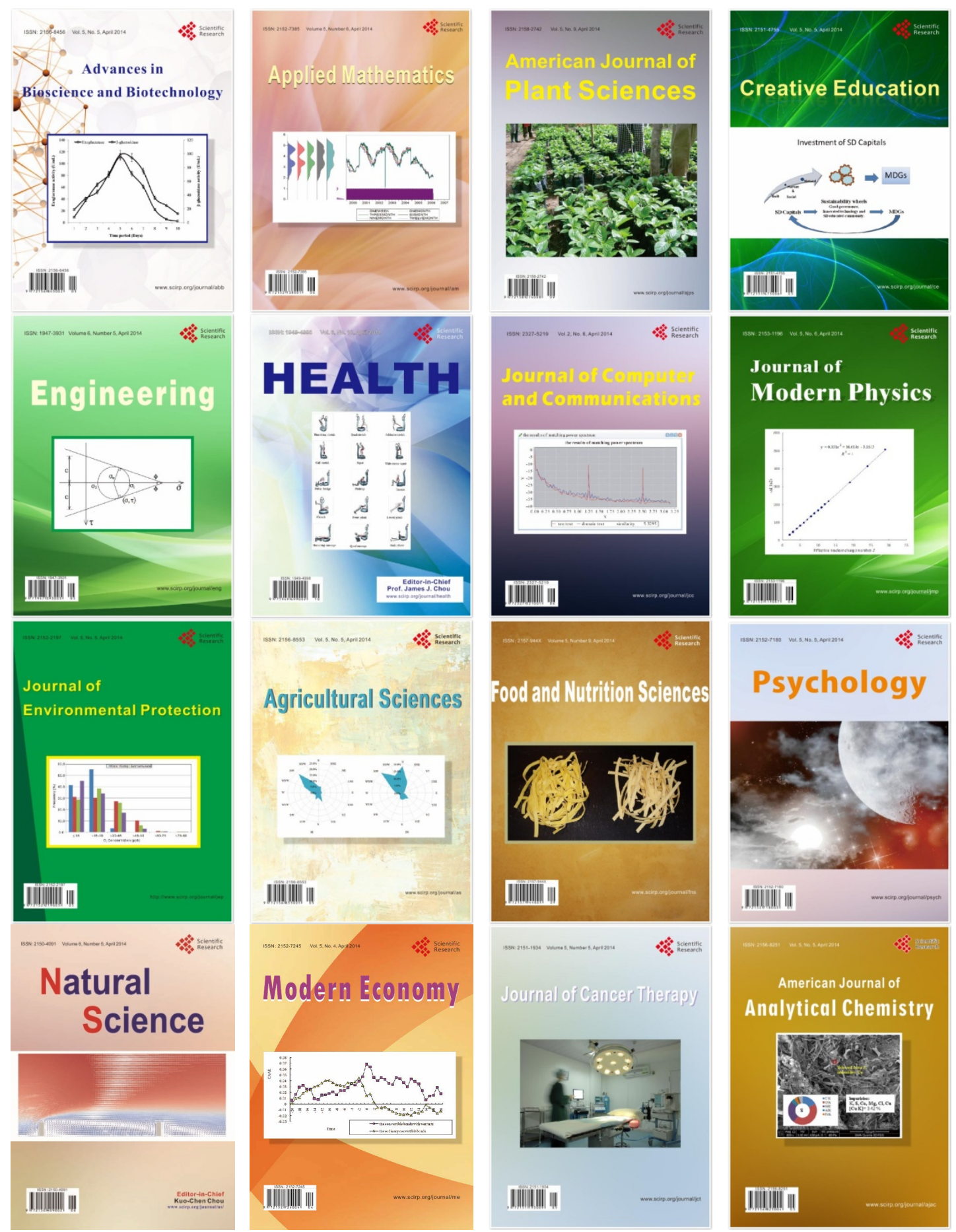